RU Структурные особенности концепта GESETZ (ЗАКОН) как основа синонимии в текстах немецкого законодательства

\author{
Березовская А. В.
}

\begin{abstract}
Аннотация. Цель исследования - установление когнитивных оснований синонимии номинаций концепта GESETZ (ЗАКОН). Анализ данного концепта проведен на материале текстов немецкого законодательства, в результате анализа выявлены когнитивные признаки и смоделирована его структура, что позволяет определить специфику вербализации данного концепта в немецких нормативно-правовых текстах. Научная новизна заключается в комплексном характере исследования репрезентаций концепта GESETZ в немецком законодательстве. Результатом исследования является построение полевой модели его номинаций в правовых текстах, выявление структурных особенностей концепта GESETZ и установление когнитивных оснований синонимии его номинаций.
\end{abstract}

\title{
EN Structural Features of the GESETZ (LAW) Concept as the Basis for Synonymy in German Legislative Texts
}

\author{
Berezovskaya A. V.
}

\begin{abstract}
The research aims to determine cognitive grounds for the synonymy of naming units belonging to the GESETZ (LAW) concept. The analysis of the said concept was carried out using the material of German legislative texts, as a result of the analysis, cognitive features have been identified and its structure has been modeled, which makes it possible to determine verbalisation specificity of this concept in German statutory and regulatory texts. Scientific novelty lies in the comprehensive nature of the study of the GESETZ concept representations in German legislation. The research findings amount to constructing a field model of its naming units in legal texts, identifying structural features of the GESETZ concept and determining cognitive grounds for the synonymy of its naming units.
\end{abstract}

\section{Введение}

Актуальность темы исследования обусловлена возросшим интересом к изучению терминологий специальных дискурсов, способов номинации и процессов категоризации различных явлений окружающей действительности. Изучение лингвистических аспектов юридического дискурса на материале различных языков способствует расширению представлений о языковой картине мира как обывателя, так и специалиста в определенной сфере, например, в области права. Концепт GESETZ относится к числу важнейших, базовых в концептосфере права, изучение его структуры помогает более глубинно исследовать сущность правовых концептов и установить основания синонимических отношений между номинациями данного концепта.

Поставленная цель предполагает решение следующих задач:

- выявление когнитивных признаков концепта с помощью дефиниционного анализа, анализа синонимов и контекстного анализа;

- установление методом сплошной выборки перечня номинаций концепта GESETZ в текстах законов;

- построение полевой модели репрезентаций концепта;

- выявление его структурных особенностей с помощью семантико-когнитивного анализа.

Анализ данного концепта проведен на материале текстов немецкого законодательства, в результате анализа выявлены когнитивные признаки и смоделирована его структура, что позволяет определить специфику вербализации данного концепта в немецких нормативно-правовых текстах и установить основания синонимических отношений между номинациями данного концепта.

Материалом исследования послужили тексты немецкого законодательства, размещенные на официальном портале Министерства юстиции и защиты прав потребителей ФРГ (https://www.gesetze-im-internet.de). 
Дефиниционный анализ проводился с привлечением данных авторитетных немецкоязычных словарей: DUDEN Deutsches Universalwörterbuch (2015), WAHRIG Deutsches Wörterbuch (Wahrig-Burfeind, 2011), PONS Großwörterbuch Deutsch als Fremdsprache (2009), LANGENSCHEIDT Großwörterbuch Deutsch als Fremdsprache (2019), Digitales Wörterbuch der deutschen Sprache (2021), а также словаря синонимов Duden. Das Synonymwörterbuch (2019). Поскольку общеязыковые лексикографические источники не всегда фиксируют релевантные для терминосистем и концептосфер понятийные признаки, с учетом специфики изучаемой языковой сферы для анализа были использованы данные комментированного глоссария, размещенного на платформе Juraforum (Rechtslexikon, 2021). По мнению С. П. Хижняка (2013, с. 208), при изучении концептуального содержания юридического термина не стоит пренебрегать данными энциклопедических словарей, поскольку именно в них не только дается дефиниция термина, но и указываются разнообразные сведения о предмете или явлении, например история возникновения и эволюции, взаимосвязи с другими правовыми категориями, понятиями, с различными общественными процессами и т.д. Руководствуясь данным положением, мы использовали в своем исследовании данные энциклопедического словаря, размещенного на платформе Wissen.de (Großes Wörterbuch..., 2021).

Теоретической базой исследования стали работы российских и зарубежных лингвистов, анализировавших структуру концептов: С. Г. Воркачева (2004; 2007), А. А. Залевской (2001), В. И. Карасика (2002), В. А. Масловой (2001), 3. Д. Поповой и И. А. Стернина (2001), Ю. С. Степанова (Семиотика, 2001); изучавших содержание и соотношение лингвокультурных концептов: Е. В. Бабаевой (2002) и П. С. Гуревича (2003); занимавшихся проблемами номинации и терминологии: А. А. Уфимцевой, Е. С. Кубряковой (Уфимцева, Азнаурова, Кубрякова, 1977), В. А. Татаринова (2006), В. Д. Девкина (2005); а также анализировавших терминологию специальной отрасли - отрасли права: Ю. А. Веденеева (2017), С. П. Хижняка (2013), Д. Буссе (Busse, 2015), Ф. Фогеля (Vogel, 2012).

Практическая значимость работы заключается в том, что ее материалы могут быть использованы при составлении специализированных словарей, при разработке спецкурсов или спецсеминаров по юридическому немецкому языку для студентов неязыковых вузов, а также для дальнейших исследований языковых явлений в виде ментальных структур.

\section{Основная часть}

Юридическая терминология находится в тесной взаимосвязи с общеупотребительной лексикой, термины зачастую формируются на основе переосмысления общеупотребительных слов, например, в процессе метафоризации, сужения или расширения их значения, поэтому термин по своему содержанию нередко отличается от общеупотребительных слов, известных широкому кругу носителей языка. У многих юридических терминов дефиниция отсутствует, и раскрытие их терминологического значения происходит на основе соотношения значения слова в общелитературном языке и в системе правовых знаний. Эти знания формируются в процессе преобразования и упорядочения таксономических структур, включающих в себя разноуровневые логические и когнитивные категории, в результате чего формируются мыслительные образования - концепты. Под юридическим концептом мы понимаем комплексную единицу мышления, содержащую всю совокупность знаний об определенном явлении правовой действительности, а под термином - элемент терминосистемы, при формировании которого одни концептуальные признаки выходят на первый план, являясь доминантными, а другие, находясь на периферии, ожидают подходящих условий для актуализации. Сложность и многоуровневость организации структуры правового концепта вынуждают законодателя прибегать к использованию схожих по своему значению языковых знаков при формулировании правовой нормы. По словам В. А. Татаринова (2006), «определение синонимов на металингвистическом уровне как единиц, коррелирующих в смысловом отношении, но различающихся периферийной семантикой, как нельзя кстати отражает сущность терминологической синонимии» (с. 173). Это связано со стремлением к наиболее полному, понятному или наиболее точному выражению воли законодателя, в результате чего в законодательных текстах встречается значительное количество синонимов.

В сложной, многомерной структуре концепта традиционно выделяют три составляющих: понятийную, образную и оценочную. Под понятийной составляющей концепта понимается языковая фиксация, его обозначение, описание, признаковая структура и дефиниция. С. Г. Воркачев (2007, с. 7) определяет ее как «признаковую и дефиницированную» структуру. Образная составляющая включает в себя когнитивные метафоры, поддерживающие концепт в сознании, они выявляются в ходе проведения психолингвистического эксперимента. Оценочная (или «значимостная») составляющая - это этимологические, ассоциативные характеристики, проявляющиеся прежде всего в паремиях. Поскольку анализ паремиологических единиц, эксплицирующих признаки концепта, или проведение психолингвистического эксперимента не являются частью нашего исследования, мы сосредоточим свое внимание на понятийной составляющей концепта. С. Г. Воркачев (2007, с. 31-32) разделяет концепты по степени их абстрактности и выделяет ментефакты в противоположность конкретным натурфактам и артефактам. Концепты юридического дискурса, в частности репрезентуемые в текстах законодательства, по большей части можно отнести к ментефактам - концептам абстрактных сущностей.

Наиболее распространенной среди исследователей структуры концепта является идея о многослойности, сформулированная в работах многих ученых (Е. С. Кубрякова, Ю. С. Степанов, И. А. Стернин, В. И. Карасик, В. В. Колесов, Г. Г. Слышкин, С. А. Аскольдов и др.). По аналогии с полевой организацией значения слова 
И. А. Стернин и 3. Д. Попова (2001, с. 36) разрабатывают полевую модель концепта. Авторы предлагают допустить, что и концепт имеет многослойную организацию, выявляемую через анализ языковых средств ее репрезентации. Исходя из данного подхода, в структуре концепта можно выделить основной «актуальный» признак, характеризующий слой концепта, активно используемый в языке определенной нации или целой культуры. В этом слое концепт, по замечанию Ю. С. Степанова (Семиотика, 2001), также разрабатывавшего идею многослойности концепта, реально существует для «всех пользующихся данным языком как средством взаимопонимания и общения» (с. 48). Затем выделяются дополнительный или «пассивный» признак или признаки, актуализирующиеся при общении людей определенных социальных групп, и, наконец, внутренняя форма, часто не осознаваемая, запечатленная во внешней, словесной форме, открывающаяся лишь исследователям в процессе этимологического анализа.

А. А. Залевская (2001) рассматривает концепт как «объективно существующее в сознании человека перцептивно-когнитивно-аффективное образование динамического характера в отличие от понятий и значений как продуктов научного описания (конструктов)» (с. 39). В. А. Маслова (2001) анализирует и изучает концепт с позиций лингвокультурологии, подчеркивая важную роль для коллективного языкового сознания ключевых концептов культуры, под которыми она понимает «обусловленные ею ядерные (базовые) единицы картины мира, обладающие экзистенциальной значимостью как для отдельной языковой личности, так и для лингвокультурного сообщества в целом» (с. 70). К ключевым концептам культуры она относит совесть, судьбу, волю, закон, свободу и др. О. В. Кондрашова (1998) отмечает, что «в современных исследованиях культурные концепты определяются обычно как многомерные смысловые образования в коллективном сознании, “опредмеченные” в языковой форме» (с. 18). Поскольку речь идет об абстрактных понятиях, основной дислокацией ключевой информации является сигнификат - понятийное ядро. Такие концепты соотносятся в сознании человека с предшествующим языковым опытом, в том числе историческим и социальным. П. С. Гуревич (2003, с. 149) выделяет две группы культурных концептов: к первой относятся философские «универсальные» категории, такие как время, пространство, движение, изменение и др., вторую группу составляют социальные «культурные» категории, это прежде всего свобода, справедливость, право, собственность и т.д.

ЗАКОН и ПРАВО можно отнести как к ключевым культурным концептам, так и к базовым концептам юриспруденции, которая, в свою очередь, является понятийным выражением юридических картин мира определенных исторических эпох существования и понимания права. Как отмечает Ю. А. Веденеев (2017, с. 11), право с позиций юриспруденции определяет социальные дистанции или нормативные границы внутри и вне наличных систем социального общения. Концепт GESETZ тесно связан с социокультурной реальностью, он детерминирует взаимодействие индивидуумов в социуме. Стандартизированные интеракции участников социума фиксируются социальными институтами как образцы поведения и оформляются в свод правил, принимаемых членами общества и являющихся обязательными к соблюдению всеми, т.е. в основе данного концепта лежит идея соблюдения или нарушения установленных в обществе норм поведения.

Изучение структуры концепта GESETZ способствует более глубокому пониманию его сущности и установлению оснований синонимии его номинаций. В дальнейшем займемся выявлением когнитивно-семантических элементов данного концепта с помощью дефиниционного анализа, который представляет собой описание лексической семантики, создающей содержательное наполнение концепта на основе словарных дефиниций. В связи с масштабностью данного концепта мы ограничимся лексемами, репрезентирующими данный концепт в значении системы правовых норм, юридического закона. Наиболее авторитетный толковый словарь DUDEN Deutsches Universalwörterbuch (2015) дает следующее определение лексемы Gesetz: "vom Staat festgesetzte, rechtlich bindende Vorschrift” (устанавливаемое государством, юридически обязывающее правовое предписание). Основные конститутивные признаки исследуемого нами концепта, выделяемые с помощью представленной дефиниции, следующие: (1) закон как устанавливаемая социальная норма; (2) государство как источник происхождения закона; (3) закон как регулятор правовых отношений в обществе; (4) закон как обязательное правило, предписание для членов общества; (5) фиксация закона в письменной форме.

Похожую дефиницию находим в словаре PONS Großwörterbuch Deutsch als Fremdsprache (2009). Определение, представленное в словаре WAHRIG Deutsches Wörterbuch (Wahrig-Burfeind, 2011), более конкретизировано: Gesetz, "vom Staat festgelegte Regel, die vorschreibt, dass oder wie etwas sein oder geschehen soll” (устанавливаемое государством правило, предписывающее, что и как должно быть или происходить). Государство не просто определяет, а точно прописывает правила поведения - акцент смещается в сторону разработанности и конкретности правовой нормы. Корпус DWDS (2021) также представляет более детальное определение закона, под ним понимается “rechtlich bindende, vom Staat und seinen Organen festgesetzte Vorschrift, Norm” (юридически обязывающее правило, норма, установленная государством и органами власти). Выделяем семы (1) юридическая сила: rechtlich в значении законный; (2) обязательность: bindend; (3) представленность государства менее крупными структурами - органами государственной власти: vom Statt und seinen Organen; (4) нормированность, формально определенное и закрепленное в законе правило поведения: festgesetzte Vorschrift, Norm.

Правовую норму (Rechtsnorm) как закон (право) определяет юридический глоссарий, размещенный на портале Juraforum (Rechtslexikon, 2021). Данное определение позволяет выделить следующие признаки концепта GESETZ: правовое регулирование gesetzliche Regelung, законодательная основа gesetzliche Grundlage, абстрактность правовой нормы generell-abstrakt, адресованность неопределенному кругу лиц и правовых случаев für eine unbestimmte Anzahl von Personen und Fällen. Наиболее известные виды правовой нормы: Gesetze, Satzungen und Verordnungen (законы, постановления и предписания). 
Примеры использования лексемы Gesetz, зафиксированные в словаре LANGENSCHEIDT Großwörterbuch Deutsch als Fremdsprache (2019) и словарях DUDEN (2015), WAHRIG (Wahrig-Burfeind, 2011), PONS (2009), а также в корпусе DWDS (2021), позволяют установить дополнительные признаки концепта GESETZ: его изменяемость: Änderung, Aufhebung, Ergänzung eines Gesetzes (изменение, отмена, дополнение к закону); процедуру принятия закона Entschliessung, Erlassung, Verabschiedung (принятие закона); Durchführung, Anwendung (исполнение и применение закона); идею нарушения Verstoß, Verletzung или соблюдения закона Einhaltung; функцию закона как гаранта порядка Ordnung; внутреннюю структуру текста закона (деление на статьи, параграфы) Paragraph. В определении Электронного энциклопедического словаря, размешенного на портале Wissen.de (Großes Wörterbuch..., 2021), акцентируется фактор абстрактности правовой нормы, несвязанность ее с каждым конкретным случаем, а также содержащаяся в тексте закона идея запрета, разрешения или указания к действию.

Анализ текстов немецких правовых актов позволяет выделить следующие частотные сочетания с лексемой Gesetz, а на их основе когнитивные признаки исследуемого концепта.

Глагольные сочетания актуализируют признаки регулирующей функции законов (etw. regeln), процесса их применения G. anwenden, соотнесенности с чем-либо berühren, определяющей роли законов в сфере нормализации общественных отношений bestimmen, предписывающей функции vorgeschrieben, (in Gesetzen) vorgesehen, ограниченности во времени (конечности закона, например, вступление в силу и утрата силы) in Kraft / außer Kraft treten, идеи нарушения закона gegen G. verstoßen.

Субстантивные сочетания репрезентируют признаки доступности и понятности законов Verständlichkeit der Gesetze, неприкосновенности Unberührtheit von Gesetzen, изменчивости законов (разработка, изменение, отмена) Änderung, Neufassung und Aufhebung, их применения Anwendung, Handhabung, Vollstreckung von Gesetzen вступления в силу / утраты силы Inkrafttreten, Außerkrafttreten.

Сочетания с прилагательными актуализируют признак соотнесенности с профессиональной деятельностью berufsbezogene, с закреплением прав профессиональных сообществ berufsrechtliche или общего распространения действия закона allgemeine Gesetze, важности отдельной правовой нормы genanntes, folgendes, aufgeführtes, entsprechendes, dieses Gesetz (названный, следующий, перечисленный, соответствующий, этот закон) или соотнесенности с нормой как правовым актом weitere, andere, übrige Gesetze (другие, остальные законы). Кроме того, на основе представленных в текстах законов примеров сочетаний выделяются признаки соотношения с другими законами Verhältnis zu anderen Gesetzen, статуса действительности закона erlassen, geltend (изданный, действующий) и соотнесенности с территорией deutsche, ausländische Gesetze (немецкие и законы других стран).

В композитах со словом Gesetz могут актуализироваться когнитивные признаки соотнесенности с отраслью права Strafgesetz (уголовное право), объектом защиты Jugendschutzgesetz (Закон о защите несовершеннолетних) или объектом регулирования Versicherungsvertragsgesetz (Закон о договоре страхования). Целевая направленность концепта манифестируется с помощью субстантивных словосочетаний Gesetz zum Schutz, zur Sicherung, Durchführung, Anpassung, Änderung, Verbesserung, Umsetzung, Neugliederung, Reform, Bekämpfung и т.д. Закон может быть направлен на защиту, обеспечение, реализацию, оптимизацию, изменение, улучшение, реализацию, реорганизацию, реформу, борьбу и т.д. Предложные сочетания с лексемой Gesetz представлены в вариантах auf Grund von, gemäss, nach, laut (на основании, в соответствии, по, согласно) и определяют факторы обоснованности, соответствия или согласованности отдельного закона или свода законов.

В. И. Карасик (2002) считает, что к формальной характеристике культурного концепта, поддающейся статистическому учету, можно отнести так называемую «номинативную плотность» (с. 133). Наличие в языке целого ряда одно- или разноуровневых средств реализации концепта, по мнению Е. В. Бабаевой (2002, с. 25), напрямую связано с его релевантностью, важностью в глазах лингвокультурного социума, а также с аксиологической либо теоретической ценностью явления, отраженного в его содержании.

Одним из наиболее часто актуализируемых когнитивных признаков концепта GESETZ является идея нарушения закона, которая вербализуется с помощью глагола verstoßen (нарушать): gegen etwas (eine Regel, ein Prinzip, eine Vorschrift o. Ä.) handeln, eine Bestimmung, Anordnung, Vorschrift verletzen - действовать против чего-либо или нарушать, например, правило, принцип или предписание.

Анализ примеров употребления данного глагола в текстах немецких законов обнаруживает разнообразие обозначений объекта нарушения, используемых в аналогичном контексте.

Номинация Gebot (предписание, закон), gegen das Rechtsfahrgebot (против закона о правостороннем движении) используется для обозначения законов, предписывающих, разрешающих определенные действия, например правостороннее движение. Кроме того, она часто употребляется как прямое противопоставление запрету: ein Gebot oder ein Verbot (предписание и запрет).

Номинация Gesetz (gegen ein Gesetz) (закон, против закона) - одна из основных прямых номинаций концепта GESETZ, встречается чаще всего в композитах с первым элементом, обозначающим объект защиты или объект регулирования, либо в виде сложных развернутых словосочетаний с ключевым связующим грамматическим элементом - предлогом ӥber (Закон о...), точно определяющих сферу действия конкретного закона, например, Dreizehntes Gesetz über die Anpassung der Renten aus den gesetzlichen Rentenversicherungen sowie über die Anpassung der Geldleistungen aus der gesetzlichen Unfallversicherung (Тринадцатый закон о корректировке пенсий по Закону о пенсионном страховании, а также о корректировке денежных пособий по Закону о страховании от несчастных случаев) (здесь и далее примеры из законов цитируются по официальным материалам, представленным на сайте Министерства юстиции и защиты прав потребителей ФРГ. - А. Б.) (https://www.gesetzeim-internet.de/index.html). В качестве связующего элемента может использоваться предлог zи, в случаях, когда 
закон направлен на какое-либо действие, например, Gesetz zur Entwicklung und Förderung der Windenergie auf See (Закон о развитии и продвижении ветровой энергетики на море). Предлог gegen манифестирует направленность действия закона на борьбу или устранение чего-либо, например, Gesetz gegen Doping im Sport (синонимичное название - Anti-Doping-Gesetz) - Закон о борьбе с допингом в спорте, или антидопинговый закон. Под прямой номинацией вслед за Е. С. Кубряковой (Уфимцева, Азнаурова, Кубрякова, 1977) мы понимаем способ, основанный на «использовании форм в их первичной функции для обозначения данного объекта в данных условиях» (с. 243). По сравнению с прямой косвенная номинация не такая точная и менее определенная, она распознается «благодаря несоответствию наименования в его первичной функции данному номинату, для обозначения которого в языке имеется другое, прямое, собственное средство обозначения» (с. 246).

Нарушаться может не весь закон, а отдельные его положения, поэтому в текстах законодательства мы встречаем использование номинации Vorschriften (положения закона) как в значении отдельных положений: gegen sonstige Vorschriften dieses Gesetzes (нарушение других положений данного закона), так и в значении всего закона gegen Vorschriften (нарушение положений = закона), gegen verkehrsrechtliche Vorschriften oder Strafgesetze (нарушение Закона о дорожном движении или Уголовного закона). Здесь мы наблюдаем метонимический перенос с части на его целое. Отношения между гиперонимами и гипонимами не относятся к синонимии, однако контекстная разновидность допускается. В. Д. Девкин (2005, с. 90-91) как раз указывает на то, что в контексте слово можно заменить, например, как при помощи гиперонима, так и в отдельных ситуациях - гипонима.

Метонимический перенос значения можно зафиксировать у номинации Bestimmung (положение, закон): gegen Bestimmungen über den Binnenschifffahrtsfunk (нарушение положений о радиосвязи во внутреннем судоходстве). В качестве синонимичной номинации используется лексема Rechtsverordnung (правовое предписание, закон) в форме множественного числа: gegen die Vorschriften dieses Gesetzes und der auf Grund dieses Gesetzes erlassenen Rechtsverordnungen (нарушать положения данного закона и изданные на основании этого закона предписания). Мы встречаем ее в примерах отдельного использования, gegen eine Verordnung или в сочетании с другими синонимичными лексемами gegen eine Verordnung oder eine Richtlinie oder eine Entscheidung oder einen Beschluss der Europäischen Gemeinschaft oder der Europäischen Union verstoßen (нарушать регламенты и директивы или решения Европейского сообщества или Европейского союза). Такое сочетание в рамках одного контекста является основанием для установления синонимичных связей между лексемами Verordnung, Richtlinie, Entscheidung, Beschluss. Кроме того, объединяющим фактором является здесь Европейское сообщество или Европейский союз в роли источника права.

Дальнейшие примеры позволяют установить синонимию номинаций Verordnung - Anordnung, Anordnung Verfügung, Beschluss - Genehmigung, Vorschrift - Entscheidung - Anordnung: erlassene Verordnungen oder vollziehbare Anordnungen (изданные или исполненные постановления), gegen Anordnungen und Verfügungen (действовать против, нарушать постановления и распоряжения), gegen den Planfeststellungsbeschluss oder die Plangenehmigung, eine Unfallverhütungsvorschrift oder gegen eine gerichtliche Entscheidung oder eine behördliche Anordnung verstoßen (нарушать решение об установлении плановых мер или плановое разрешение, правила безопасности, судебное решение или распоряжения других ведомств). На основании приведенных примеров можем зафиксировать актуализацию дополнительных когнитивных признаков концепта GESETZ: источник права behördlich, стадии правоприменения: судебное рассмотрение и вынесение решения - gerichtlich или принятия и применения постановления: erlassen, vollziehbar (изданное, исполненное).

Синонимия между прямыми и косвенными номинациями концепта GESETZ может строиться не только на основании соотношений часть-целое, перенос значения может инициироваться ассоциациями и обосновывать образность, метафоричность употребляемых номинаций. Такие примеры, как gegen die im Rahmen der Überwachung obliegenden Pflichten (нарушать обязанности, налагаемые надзорными функциями), gegen seine Mitwirkungspflicht (нарушать обязательства по участию), gegen diesen Grundsatz (нарушать данный принцип), gegen die Grundsätze der Menschlichkeit oder Rechtsstaatlichkeit (или принципы человечности и правового государства), gеgen zwingende Grundsätze des Handelsrechts (обязательные принципы торгового права), gegen die Grundsätze des § 1 Abs. 3 (принципы согласно § 1 абз. 3), gegen Verpflichtungen, gegen Auflagen (обязательства или требования), gegen die Fristen nach § 59 Absatz 2 (сроки), gegen die Ordnung (порядок), позволяют зафиксировать номинации, вербализующие концепт GESETZ в текстах законов: Pflichten, Verpflichtung, Auflagen, Grundsatz, Grundsätze, Fristen, Ordnung. Обязанности и обязательства устанавливаются на основе правовых норм, законов, принцип, принципы и сроки должны соблюдаться, в противном случае закон нарушается, порядок гарантируется и обеспечивается законом. Данные номинации являются контекстными синонимами к слову «закон» на основании метафорического переноса. Употреблению данных номинаций часто сопутствует актуализация других когнитивных признаков концепта GESETZ. Серьезность и неоднократность нарушений, их значительность и постоянность актуализируют признак принятия/непринятия правовых норм обществом и отдельными индивидуумами и, как следствие, регулярность несоблюдения закона: schwer oder wiederholt verstoßen (нарушать серьезно и неоднократно), in gefährdender Weise, nachhaltig, erheblich oder dauerhaft verstoßen (угрожающим образом, постоянно и существенно), wiederholt nicht ordnungsgemäß durchführen (регулярно не выполнять надлежащим образом). Другие актуализируемые факторы - действительность (geltend) нарушаемых норм и их корреляция с разными сферами права (экологическое, социальное, трудовое) geltende umwelt-, sozial- oder arbeitsrechtliche Verpflichtungen.

Вектор метонимического переноса значения может быть направлен не от целого к части, а в обратную сторону. Постановления и регламенты объединяются общим гиперонимом Rechtsakte (правовые акты), unmittelbar geltende Rechtsakte der Europäischen Gemeinschaft (непосредственно действующие в рамках европейского сообщества), 
а гипероним Rechtsvorschriften (правовые предписания, положения) является общим обозначением для Verordnungen und Richtlinien (регламентов и директив). Кроме того, закон может заменяться ключевым словом из его названия: gegen das Waffenembargo: нарушать эмбарго на поставки оружия означает нарушать закон, запрещающий импорт, покупку или транспортировку вооружений и связанных с ними материалов всех типов.

Словарь синонимов Duden. Das Synonymwörterbuch (2019) приводит 28 синонимов к слову Gesetz. Из них мы отобрали те, что коррелируют с семами слова Gesetz в рассматриваемом нами значении. К ним относятся Bestimmung (положение), Erlass (указ), Gebot (указ, предписание), Verordnung (постановление, регламент), Anordnung (распоряжение), Vorschrift (предписание), Direktive (директива), Novelle (новелла), Richtlinie (директива), Paragrafenwerk (параграф), Grundsatz (принцип), Prinzip (принцип), Richtschnur (директива), Standard (стандарт), Edikt (эдикт), Dekret (декрет), Statut (статут). По результатам статистического анализа использования релевантных для текстов законов репрезентаций концепта GESETZ можно констатировать следующее: в значении правового акта в немецком законодательстве употребляются лексемы Gesetz (34345), Bestimmung (2531), Verordnung (43810), Vorschrift (1572), Paragraph (88), Richtlinie (3098), Anordnung (4039), Erlass (1606), Statut (244), Direktive (7) и Edikt (1). Статистические данные получены в ходе анализа частотности употребления номинаций концепта GESETZ в характерных для значения «законодательный акт» контекстах текстов законов, размещенных на официальном сайте Министерства юстиции и защиты прав потребителей ФРГ (https://www.gesetze-im-internet.de/index.html).

Выявленные нами ранее наиболее распространенные репрезентации концепта GESETZ в значении нормативный акт Gesetz и Verordnung чаще всего встречаются в следующих конструкциях: nach dem Gesetz, nach der Verordnung (согласно закону) или im Sinne dieses Gesetzes, im Sinne dieser Verordnung (для целей настоящего закона). Richtlinie обозначает законодательный акт ЕС. Сочетания nach der Richtlinie, im Sinne der Richtlinie аналогичны упоминаемым ранее сочетаниям с лексемами Gesetz и Verordnung. Лексемы Gesetz - Verordnung Richtlinie образуют синонимический ряд, доминантой в котором является Gesetz.

Лексема Paragraph зафиксирована в сочетании im Sinne des Paragraphen, по аналогии с im Sinne des Gesetzes. Текст закона традиционно делится на части и параграфы или части, статьи и абзацы. В параграфе может быть сформулирована важная часть правовой нормы, к которой идет отсылка в тексте закона, поэтому сочетание im Sinne des Gesetzes заменяется синонимичным ему im Sinne des Paragraphen. В синонимичной паре Gesetz - Paragraph, сформировавшейся на основе контекста, мы наблюдаем уже рассмотренное взаимодействие концептуальных признаков: часть - целое. Синонимичные отношения становятся возможными благодаря явлению метонимии. Подтверждает возможные в определенных контекстах отношения синонимии между лексемами Gesetz и Paragraph перечисление их в списке синонимов к словам rechtlich (правовой) и rechtmässig (законный): nach dem Gesetz, nach den Paragrafen.

Лексема Erlass (указ) встречается в текстах законов достаточно часто, правда, в большинстве случаев она вербализует концептуальный признак ПРИНЯТИЕ ЗАКОНОВ, ПОСТАНОВЛЕНИЙ. Ermächtigung zum Erlass von Rechtsverordnungen (разрешение на принятие правовых постановлений), Erlass von den Entscheidungen, Anordnungen, Gesetzen, Richtlinien (принятие решений, распоряжений, законов, руководящих принципов). Но в определенных контекстах лексема Erlass может уравниваться с другими номинациями, вербализующими закон как нормативно-правовой акт, это можно зафиксировать в примере Erlass über die Genehmigung einer Neufassung des Erlasses (Указ о разрешении пересмотра указа), таким образом, Gesetz - Erlass образуют пару синонимов.

Выбивается из разряда номинаций концепта GESETZ слово Statut. Дефиниция, представленная в словаре DUDEN (2015) - “Satzung, Festgelegtes, Festgesetztes (z. B. bezüglich der Organisation, eines Vereins)” (что-то установленное, например, в отношении организации или объединения), достаточно абстрактна и размыта. На основе данной дефиниции можно установить единственный когнитивный признак - закрепленности нормы, признак источника права или объекта регулирования отсутствует. Под статутом традиционно понимается свод непреложных правил, норм поведения, внутренний закон, на основании которого функционирует отдельная организация или сообщество. Использование данной номинации в контексте европейского права Statut der Europäischen Genossenschaft, Statut der Europäischen Gesellschaft (Устав европейского сообщества) повышает ее до уровня нормативно-правового акта. В масштабах европейского права под статутом понимается международный договор, регулирующий деятельность какой-либо международной организации и дающий ей право на проведение собственных мер и процедур, имеющий статус закона. Сочетания nach dem Statut и die Abwicklungsanstalten halten die Vorgaben aus Gesetz und Statut ein (расчетные учреждения соблюдают требования закона и устава) позволяют определить отношения между лексемами Gesetz и Statut как синонимичные.

Концепт GESETZ может вербализовываться в текстах немецкого законодательства с помощью номинации Direktive. Она сочетается с обозначением отдельного органа власти Direktive des Ministerrates (директива Совета министров), проявляя специфическую сему конкретного источника власти; сочетание auf Grund der Direktive (на основании директивы, ср. auf Grund des Gesetzes - на основании закона) позволяет определить данную лексему как синонимичную к слову Gesetz. В текстах немецкого законодательства встречается историзм Edikt (эдикт, указ). Данная номинация представлена в единственном законе Gesetz über Regelung der Rechtsverhältnisse nicht mehr bestehender öffentlicher Rechtsträger (Закон о регулировании правовых отношений больше не существующих публичных юридических лиц) и используется для обозначения уже не действующих законов: эдиктов 1799 и 1826 годов.

В результате проведенного анализа номинаций концепта GESETZ, выявленных в текстах немецкого законодательства, номинативное поле можно представить следующим образом (Схема 1). 


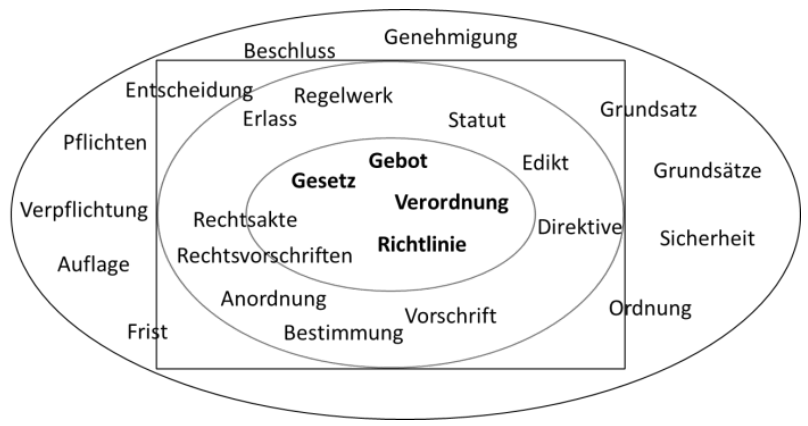

Схема 1. Полевая модель номинаций концепта GESETZ в текстах немецкого законодательства

На представленной схеме прямые и наиболее частотные номинации Gebot, Gesetz, Verordnung, Richtlinie образуют центральную, ядерную часть, околоядерное пространство заполняют менее частотные обозначения, например, Statut, Edikt, Direktive, Regelwerk, Erlass или номинации, возникшие на основании метонимического переноса. На пересечении околоядерной и ядерной зоны располагаются номинации Rechtsakte и Rechtsvorschriften, являющиеся объединяющими названиями разных видов правовых актов. Периферийное, ассоциативное поле составляют номинации, возможные в определенных контекстах, возникающие на основании ассоциаций, метафорического переноса значения, например, Ordnung или Verpflichtung. В основном, они являются контекстными синонимами к слову Gesetz - ключевой номинации концепта GESETZ.

\section{Заключение}

По результатам проведенного анализа можно сделать следующие выводы:

1. Один из базовых юридических концептов GESETZ имеет сложную структуру. В силу специфичности рассмотренной области реализации данного концепта - сферы права - можно констатировать, что словари отражают далеко не все конститутивные семы, многие когнитивные признаки устанавливаются лишь в ходе анализа текстов законов.

2. Концепт GESETZ вербализуется в текстах законов целым рядом прямых и косвенных номинаций, образующих синонимические пары или ряды.

3. Основанием синонимии может являться метонимический перенос, варианты направленности вектора переноса значения могут варьироваться как от целого к части, так и в обратную сторону.

4. Еще одним основанием синонимии служит метафора. Ассоциации связываются как с содержательным наполнением законов, с объектом их регулирования, так и с организующей функцией гарантии и обеспечения порядка в сфере общественных отношений.

5. В построенной на основании анализа номинаций концепта GESETZ модели вербализующие его единицы располагаются в трех полях-областях: ядерной, приядерной и периферийной. Удаленность каждого элемента обоснована частотностью его употребления, а также точностью обозначения исследуемого концепта (прямые и косвенные номинации).

В перспективе дальнейшего изучения концепта GESETZ может быть проанализирована его фреймовая структура, а также произведен сравнительный анализ с близкими и не менее важными макроконцептами RECHT (право) и GERECHTIGKEIT (правосудие, справедливость) с целью установления областей возможного пересечения, смешения их концептуальных пространств (концептуальной интеграции) на материале текстов немецких законов.

\section{Источники | References}

1. Бабаева Е. В. Отражение ценностей культуры в языке // Язык, коммуникация и социальная среда. 2002 . № 2.

2. Веденеев Ю. А. Юридическая наука: введение в концептуальную историю // Lex Russica. 2017. № 3 (124).

3. Воркачев С. Г. Лингвокультурный концепт: типология и области бытования. Волгоград: Изд-во Волгоград. гос. ун-та, 2007.

4. Воркачев С. Г. Счастье как лингвокультурный концепт. М.: Гнозис, 2004.

5. Гуревич П. С. Культурология: учебник для вузов. М.: Проект, 2003.

6. Девкин В. Д. Немецкая лексикография. М.: Высшая школа, 2005.

7. Залевская А. А. Психолингвистический подход к проблеме концепта // Методологические проблемы когнитивной лингвистики / под ред. И. А. Стернина. Воронеж: Изд-во Воронеж. ун-та, 2001.

8. Карасик В. И. Языковой круг: личность, концепты, дискурс. Волгоград: Перемена, 2002.

9. Кондрашова О. В. Семантика поэтического слова (функционально-типологический аспект): автореф. дисс.. д. филол. н. Краснодар, 1998.

10. Маслова В. А. Лингвокультурология: учеб. пособие для студ. высш. учеб. заведений. М.: Академия, 2001. 
11. Попова 3. Д., Стернин И. А. Интерпретационное поле национального концепта и методы его изучения // Культура общения и ее формирование / сост. и науч. ред. И. А. Стернин. Воронеж, 2001. Вып. 8.

12. Семиотика: антология / сост. Ю. С. Степанов. Изд-е 2-е, испр. и доп. М. - Екатеринбург: Академический проект; Деловая книга, 2001.

13. Татаринов В. А. Общее терминоведение. Энциклопедический словарь. М.: Московский Лицей, 2006.

14. Уфимцева А. А., Азнаурова Э. С., Кубрякова Е. С. Языковая номинация (общие вопросы) / отв. ред. Б. А. Серебренников, А. А. Уфимцева. М.: Наука, 1977.

15. Хижняк С. П. Терминологическое значение, концептуальное содержание и дефинитивная основа системности юридической терминологии // Вестник Саратовской государственной юридической академии. 2013. № 2 (91).

16. Busse D. Semantik des Rechts - Bedeutungstheorien und deren Relevanz für Rechtstheorie und Rechtspraxis // Handbuch Sprache und Recht / hrsg. von E. Felder, F. Vogel. Berlin - Boston: De Gruyter, 2015.

17. Duden. Das Synonymwörterbuch // Der Duden: in 12 Bdn. 7. Auflage. Mannheim: Dudenverlag, 2019. Bd. 8.

18. DUDEN Deutsches Universalwörterbuch. Das umfassende Bedeutungswörterbuch der deutschen Gegenwartsprache. 8., überarbeitete und erweiterte Auflage. Berlin: Dudenverlag, 2015.

19. DWDS Digitales Wörterbuch der deutschen Sprache. 2021. URL: https://www.dwds.de/wp

20. Großes Wörterbuch der deutschen Sprache. 2021. URL: https://www.wissen.de/lexikonsuche/lexicon/all

21. LANGENSCHEIDT Großwörterbuch Deutsch als Fremdsprache. München - Wien: Langenscheidt, 2019.

22. PONS Großwörterbuch Deutsch als Fremdsprache. Stuttgart: PONS GmbH, 2009.

23. Rechtslexikon. 2021. URL: https://www.juraforum.de/lexikon/

24. Vogel F. Das Recht im Text. Rechtssprachlicher Usus in korpuslinguistischer Perspektive // Korpuspragmatik. Thematische Korpora als Basis diskurslinguistischer Analysen / hrsg. von E. Felder, M. Müller, F. Vogel. Berlin: De Gruyter, 2012.

25. Wahrig-Burfeind, R. WAHRIG Deutsches Wörterbuch. München, 2011.

\section{Информация об авторах | Author information}

RU Березовская Анастасия Викторовна ${ }^{1}$

${ }^{1}$ Московский государственный институт международных отношений (университет) МИД России

EN Berezovskaya Anastasia Viktorovna ${ }^{1}$

${ }^{1}$ Moscow State Institute of International Relations (MGIMO University)

${ }^{1}$ frau.berezovskaya@yandex.ru

\section{Информация о статье | About this article}

Дата поступления рукописи (received): 04.10.2021; опубликовано (published): 30.11.2021.

Ключевые слова (keywords): правовой концепт; когнитивный признак; юридический дискурс; синонимия; полевая модель; legal concept; cognitive feature; legal discourse; synonymy; field model. 